\title{
ENHANCING SIMULATION AS A DECISION-MAKING SUPPORT TOOL FOR A CROSS- DOCKING CENTER IN A DYNAMIC RETAIL-DISTRIBUTION ENVIRONMENT
}

\author{
Yan Liu \\ Soemon Takakuwa \\ Nagoya University \\ Graduate School of Economics and Business Administration \\ Furo-cho, Chikusa-ku, Nagoya, Aichi, 464-8601, JAPAN
}

\begin{abstract}
To ensure just-in-time shipments from a general non-automated retail-cross-docking center, different items must be handled efficiently by different processes despite the many inbound shipments and frequent demand orders from retail stores. In this paper, a systematic and flexible procedure is proposed that efficiently provides critical decision-making support to logistics managers to help them understand and validate the material handling operation at a real retail-cross-docking center. The proposed procedure considers dynamic logistics operation information, such as inbound schedules of suppliers, demand data from retail-chain stores, and individual operator schedules. This detailed data is required for the performance of simulation. In addition, the procedure is applied to an actual non-automated retail-cross-docking center to confirm its effectiveness. Furthermore, the proposed method was found to be both practical and powerful in assisting logistics managers with their continuous decision-making efforts.
\end{abstract}

\section{INTRODUCTION}

In a cross-docking operation, the incoming shipment is unloaded, broken down, and immediately reassembled in outbound shipments to their respective stores (Cooper 1994). The primary objective of crossdocking is to eliminate storage, excessive handling, and lead time while minimizing transportation and storage costs and maintaining a high level of customer service.

Over the past decade, cross-docking appeared primarily in the retail distribution environment (Kulwiec 1994). At present, many retail-cross-docking centers are still non-automated because flexibility is needed to handle the increasing variety of inbound items, which depending on how small the quantities are, may require different operation rules. Non-automated retail-cross-docking centers are facing more challenges than ever in today's competitive environment. For example, many suppliers must be managed and coordinated by a single cross-docking center to satisfy customer demands; each item type must be handled by different processes to optimize the operations within a non-automated retail-cross-docking center. Hence, to increase customer service level satisfaction, a cross-docking center must ship frequently, which requires a high volume of items that must be handled quickly. In this environment, the effectiveness and efficiency of operations and execution has a significant impact on the customer service and the profitability of the entire supply chain. This study incorporates a flexible simulation-based approach in a critical decision-making support tool to understand and validate the material handling operation at a typical non-automated retail-cross-docking center from a practical point of view. 


\section{Liu and Takakuwa}

\section{BRIEF LITERATURE REVIEW}

Simulations have traditionally been used as a decision-making tool for logistics operations to allow continuous operations. Many studies have used a simulation to model a storage and retrieval system (AS/RS) (Harmonosky and Sadowski 1984, Medeiros, Enscore, and Smith 1986, Muller 1989, Takakuwa 1994, Takakuwa 1995, Takakuwa 1996, Burnett and LeBaron 2001, Macro and Salmi 2002, Amato et al. 2005, Gebennini et al. 2008, Johnson et al. 2009). In particular, Takakuwa et al. (2000) reported that it is much more difficult to build simulation models for a non-automated distribution warehouse. Zhou, Setavoraphan, and Chen (2005) discussed the conceptual simulation modeling of warehousing operations commonly seen at the general merchandise distribution centers. Takakuwa et al. (2000) and Medina et al. (2009) applied simulation models to a complicated non-automated distribution warehouse. All the mentioned papers demonstrated that simulations are a powerful and pragmatic tool for analyzing automated or non-automated warehouse operations. The simulation-based approach has also played a significant role in analyzing performance at cross-docking centers. There are several studies where simulation modeled a cross-docking system (Rohrer 1995, Magableh and Rossetti 2005, Liu and Takakuwa 2009). The purpose of this paper differs from previous research because a simulation-based approach is used to analyze the material handling operation at a typical non-automated retail-cross-docking center.

This paper discusses a simulation-based approach that provides critical support that helps logistics managers make efficient management decisions. First, the basic description of the operations and goods flows at a cross-docking center is discussed. Then, a systematic and flexible procedure is proposed and validated on a material handling operation at an actual retail-cross-docking center. The procedure uses dynamic logistics operation information, such as inbound schedules of suppliers, demand data of retailchain stores, and individual operator schedules. The procedure is applied to an actual cross-docking center to confirm its effectiveness. The proposed method was found to be both practical and powerful in assisting managers with their planning efforts.

\section{BASIC DESCRIPTION OF THE CROSS-DOCKING CENTER}

\subsection{Operations}

A general view of a cross-docking center is shown in Figure 1. In this study, the cross-docking center of HAMAKYOREX Co. Ld, which handles fresh, chilled foods, such as beverages, soft drinks, and sweet desserts, is investigated. At this cross-docking center, the daily operation activities are critical to managers, where operations are ongoing for 24 hours a day, 7 days a week, and 3 shipping services per day. All of the approximately 300 items must be received, sorted, and shipped to 236 stores across the Tokai region of Japan by a given time. For instance, the first service starts at 12:45 AM, and all operating activities must be finished before 7:45 PM, referred to as the "limit time for 1st service", to ensure that all items can be shipped on time. According to the logistics manager, over 110,000 vats (a vat is a standard container of items) of throughput were handled each day of last year. Figure 2 shows the schematic operation flow at the cross-docking center. The different items from multiple suppliers are unloaded, received, and sorted. Sorting is accomplished in two sequential steps called the preparation (prep.) sorting process and the sorting process. In the prep. sorting process, items are sorted according to their distribution zones. Next, the sorting process sorts items according to their store destination within a distribution zone. Afterwards, the completion operation is conducted, and then the merchandise for each chain store is loaded in turn.

Several operating rules are firmly established according to the content of products, packing materials, and inbound quantities to ensure smooth operations at the cross-docking center. For instance, if the products are beverages and are too heavy to be transported easily, the prep. sorting process is combined with its checking process. If the packing material is cardboard, then unpacking the cardboard is required in its prep. sorting process. If the inbound quantity is small, then checking and sorting are performed at a special handling station to avoid operation confusion with other products. Hence, the following general 


\section{Liu and Takakuwa}

products (merchandise mix) can be classified according to their required operating rules: (1) beverage products; (2) returnable-packing products; (3) cardboard-packing products; (4) small-quantity-order products. Besides the general products, fresh products are highly perishable and time sensitive goods and are therefore sorted by the fresh products factory beforehand, arriving at the cross-docking center as final products.

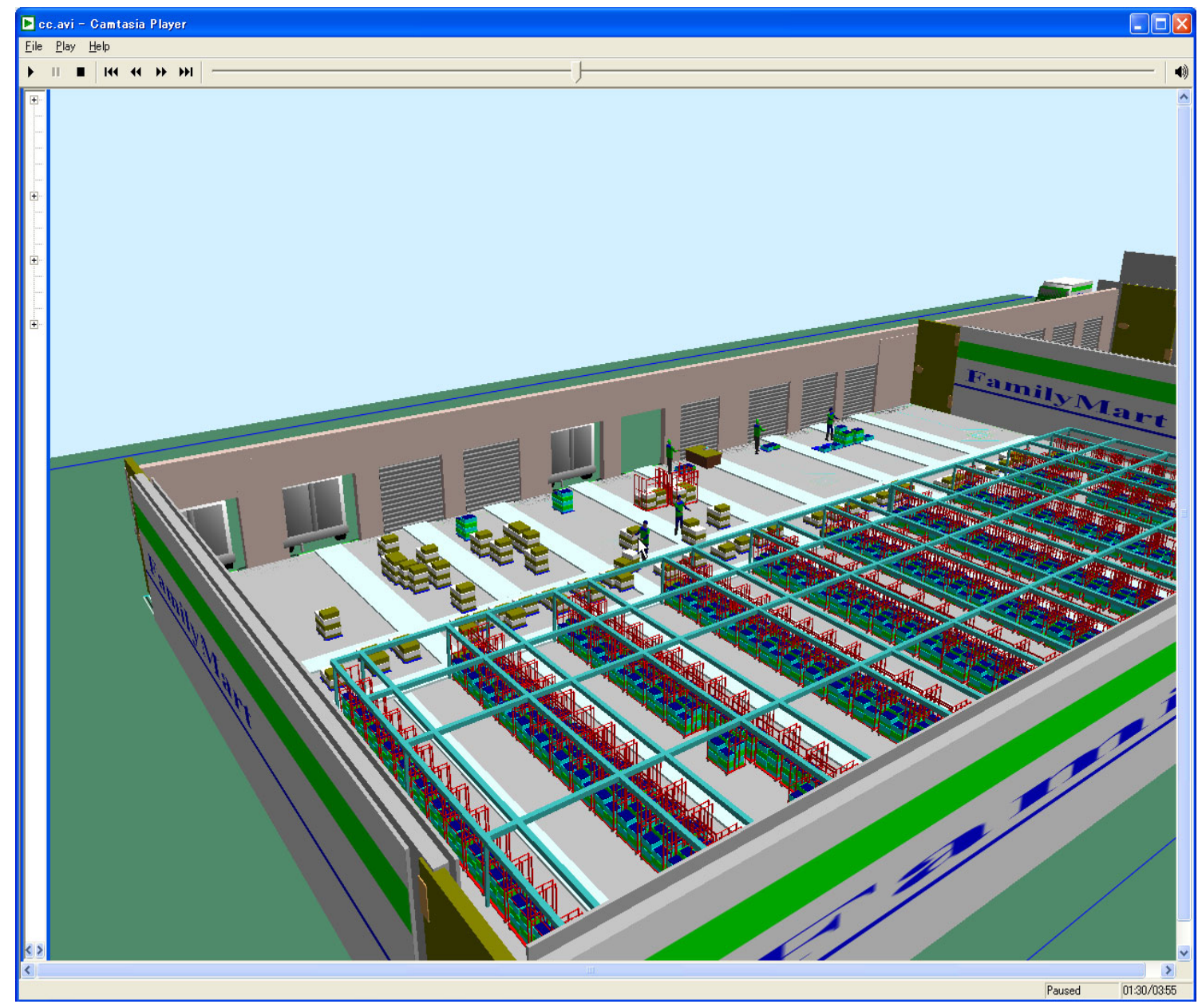

Figure 1: Part of the Animation That Shows a General View of a Cross-docking Center

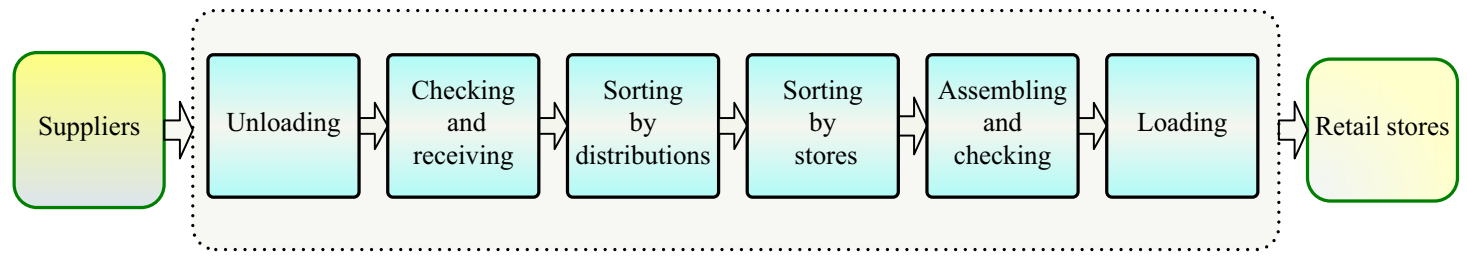

Figure 2: Operation Flow of the Cross-docking Center

At this cross-docking center, there are two operator groups. The prep. sorting group is assigned the checking, prep. sorting, and completion operation while the sorting group is assigned the sorting operation. The cross-docking center has an adopted digital sorting system that improves the performance of the sorting group. However, the manager wanted to improve the performance of the prep. sorting process by 


\section{Liu and Takakuwa}

introducing better scientific management tools. This paper emphasizes the prep. sorting operation and takes into account the skill levels of the prep. sorting group members. The operator skills of a prep. sorting group are shown in Table 1.

Table 1: Skill Types for Operators

\begin{tabular}{l|c|c|c}
\hline \multicolumn{1}{c|}{ Operations } & Type A & Type B & Type C \\
\hline Checking Operation & - & - & $\bigcirc$ \\
\hline Prep. sorting Operation & $\bigcirc$ & $\bigcirc$ & $\bigcirc$ \\
\hline Completion operation (document filing, cleaning) & - & $\bigcirc$ & $\bigcirc$ \\
\hline
\end{tabular}

\subsection{Essential Process Flows}

In this section, the essential process flow is identified so the material handling at a typical non-automated cross-docking center can be characterized. The checking and preparation sorting operations are the two essential process flows that are typically performed in a retail-based cross-docking system and are shown in Figure 3.
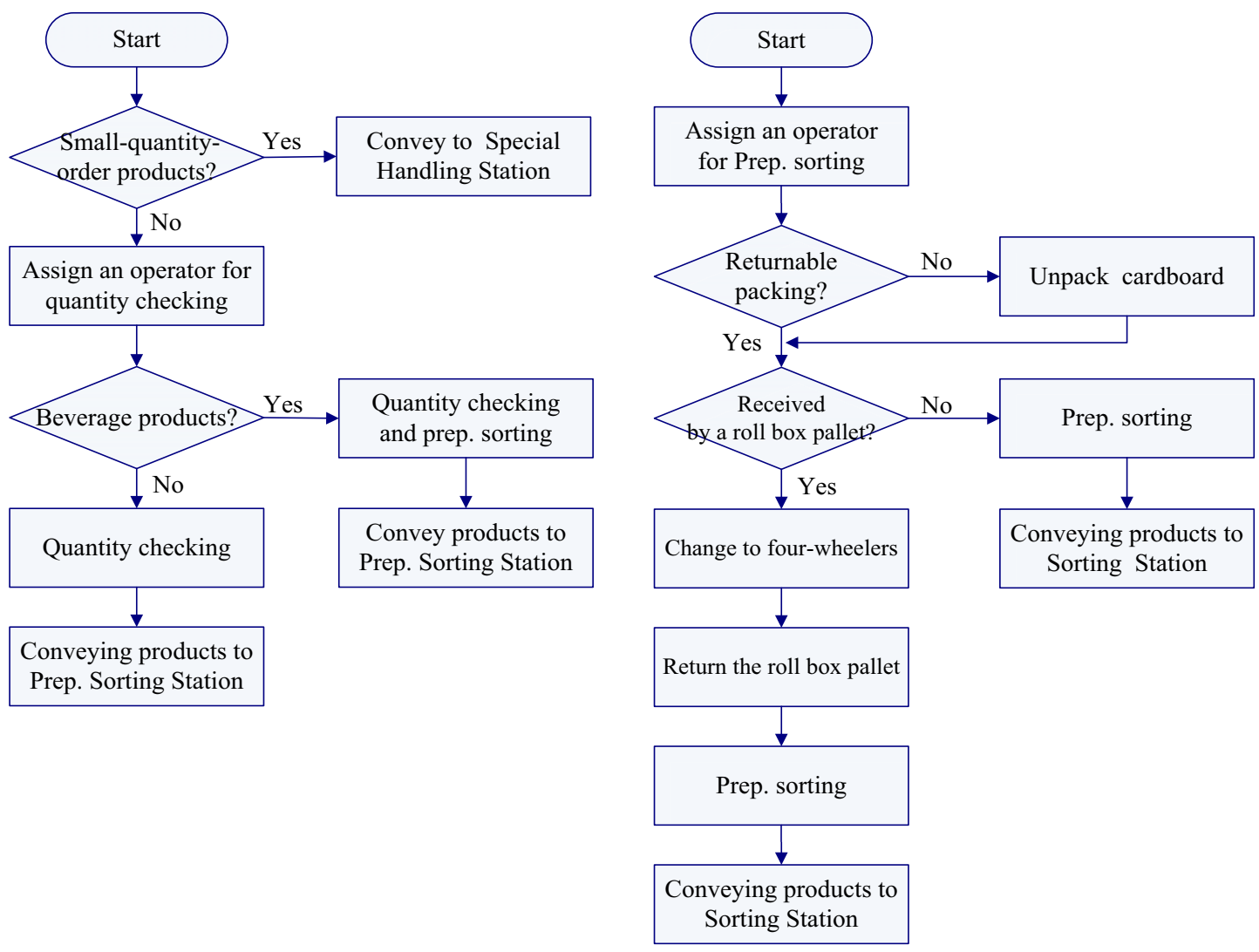

(a) Checking operation

(b) Prep. sorting operation

Figure 3: Essential Process Flows

Each process flow contains a sequence of activities performed by two sets of shared operator groups. All operating activities must be completed in a fixed amount of time so items for each store are shipped on time. From Figure 3, the checking operation begins when one item is unloaded from an inbound truck. An assigned operator will then count the inbound quantity and sign for the inbound documents, called the "checking operation". Following this step, the prep. sorting operation is performed, which consist of the 


\section{Liu and Takakuwa}

following two operating activities: (1) sorting by distribution zone for general merchandise, which includes small-quantity-order products; returnable-packing products; cardboard-packing products and beverage products; and (2) pasting labels for fresh products. In the prep. sorting operation, the completion operation, which includes inbound document filling and clearing, is also implemented. The sorting operation follows the prep. sorting operation and consists of the following two operating activities: (1) sorting by store at distribution zones; and (2) pasting labels of each store for general merchandise.

\section{PROCEDURE AS A DECISION-MAKING SUPPORT TOOL}

\subsection{Proposed Procedure}

Computer simulation is a methodology that can be used to describe, analyze, and predict the performance of a complex system without limiting assumptions. The objective of this study is to propose procedures, which uses dynamic logistics operation information, that would act as a decision-making support tool for managers. The procedures would help managers understand and validate the material handling operations. As shown in Figure 4, the procedures to validate and improve the material handling operation are itemized as follows:

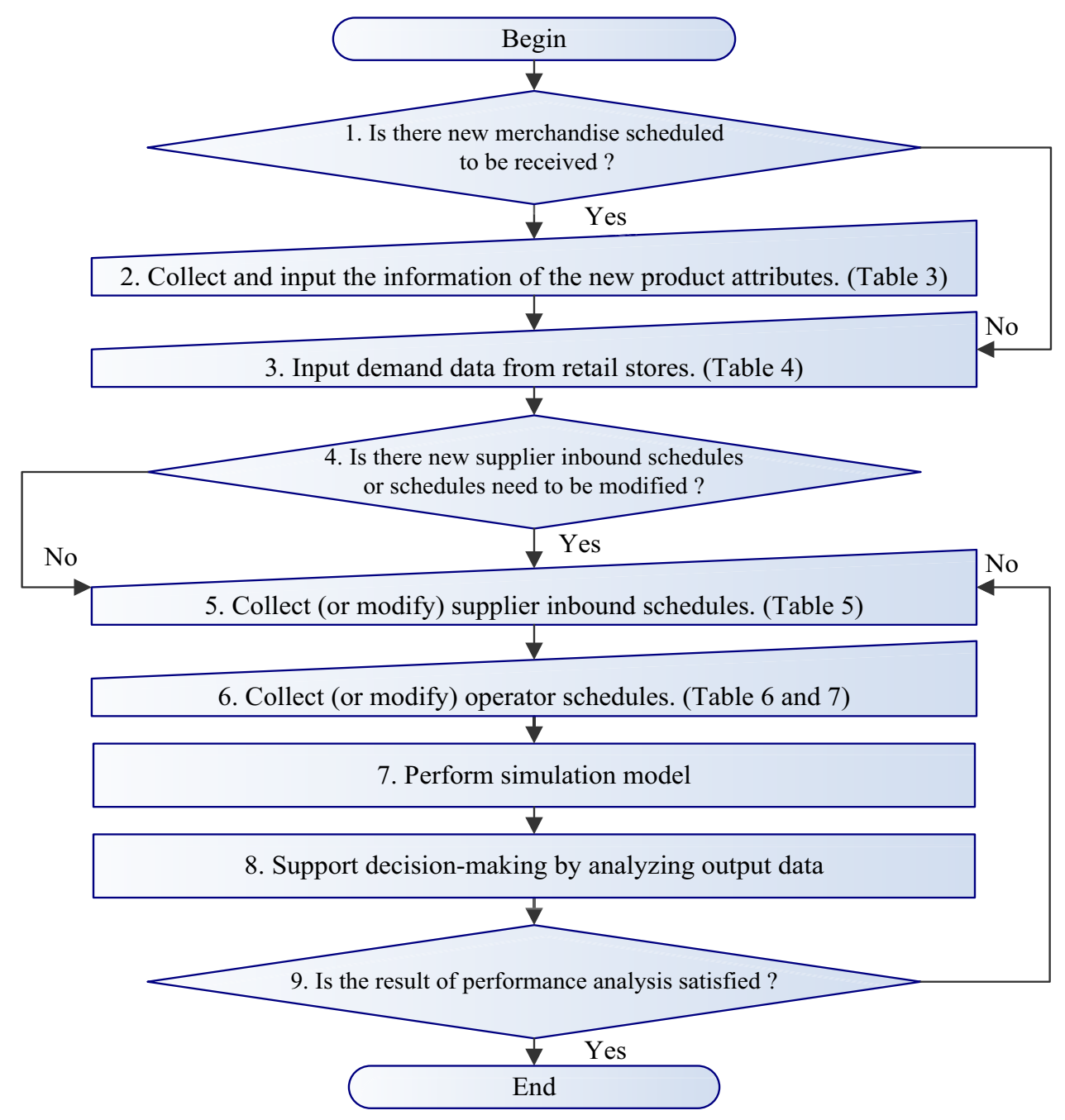

Figure 4: Proposed Procedure to Seek the Optimal Solution 


\section{Liu and Takakuwa}

[Step 1] If there are new products to be received, go to Step 2. Otherwise go to Step 3.

[Step 2] Collect and input the new product attributes information based on the operation rules, as described in section 3.1 .

[Step 3] Input the order data from the customers (typically from retail stores) obtained from the logistics information system (LIS) of the cross-docking center.

[Step 4] If there are new truck inbound schedules or schedules that need to be modified, go to Step 5. Otherwise go to Step 6.

[Step 5] Collect or modify supplier inbound schedules.

[Step 6] Accept each operator's request for working hours in advance.

[Step 7] Perform a simulation to observe the material handling operations animation.

[Step 8] Obtain simulation results for management decision making.

[Step 9] If the result from the performance analysis is acceptable (improves performance of the material handling operations), terminate the procedure. Otherwise return to Step 5 and adjust the supplier inbound schedules.

\subsection{Simulation Logic}

A simulation model of material handling for the retail cross-docking center was created using the simulation package, Arena (Kelton, Sadowski, and Sturrock 2007). To analyze the operating time of the essential process flows, all operations were recorded within the cross-docking center with a video camera for the first service for five days. Based on the video analysis, selection times were analyzed with Arena input analyzer. Selected parts from the simulation logic at Step 7 are shown in Figure 5. By performing a simulation, the man-hour requirement for each operating activity for each work-hour is outputted. The resulting ending times for each operation are compared to the actual system behavior obtained by video to validate the simulation model.

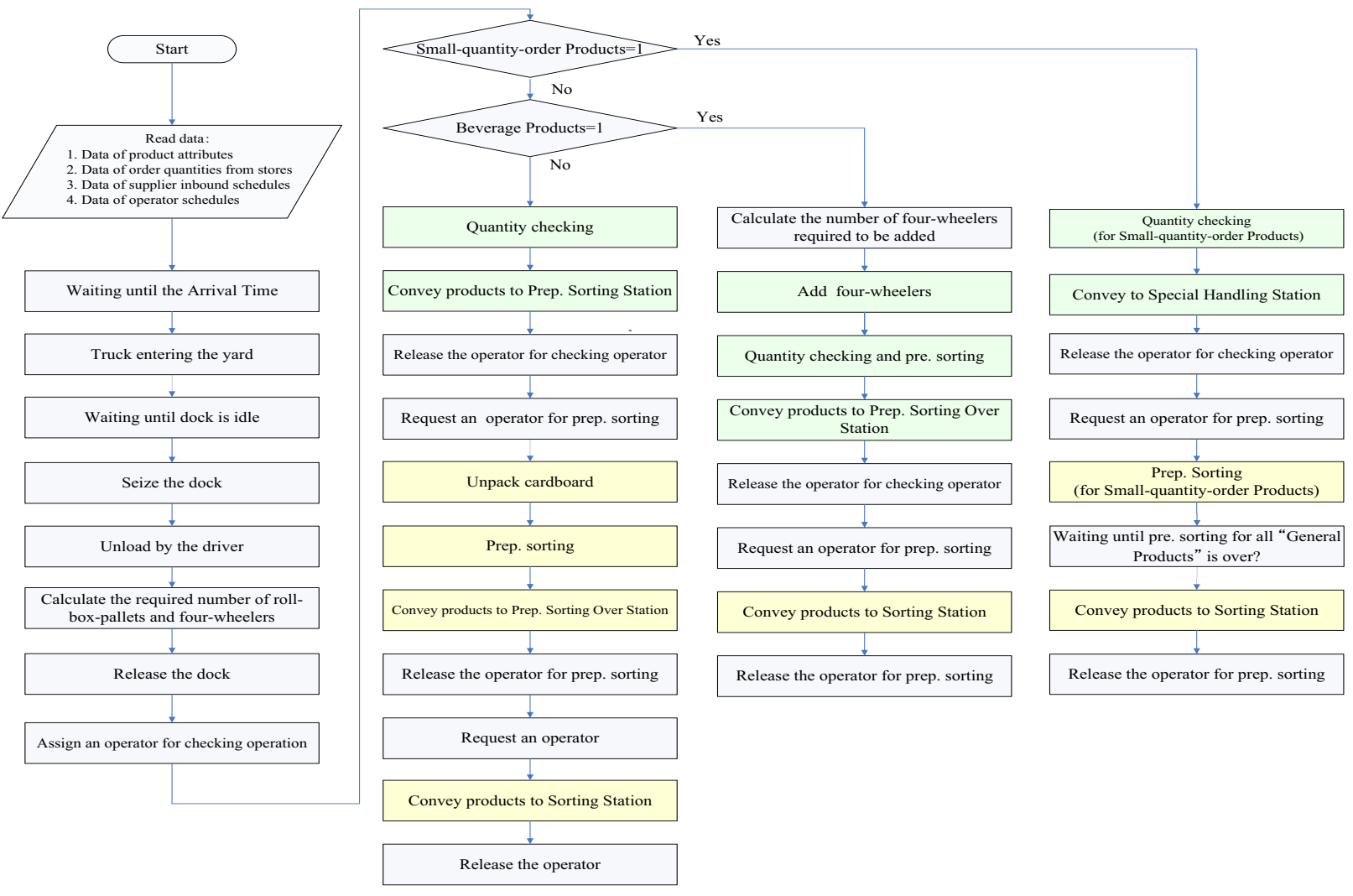

Figure 5: Selected Parts of Simulation Logic 


\section{Liu and Takakuwa}

\section{APPLICATION}

\subsection{Data Collection}

Several selected parameters that relate to the essential process flows are shown in Table 2. At Steps 1 and 2 , the new merchandise attributes were collected and inputted, which were analyzed to build the simulation model, as shown in Table 3. Proceeding to Step 3, Table 4 shows the order data from customers (namely from retail stores) obtained from the logistics information system (LIS) of the cross-docking center. At Steps 4 and 5, the new truck inbound schedules are confirmed and added. The arrival times of suppliers are shown in Table 5. To perform a simulation, each operator's request on working hours should be accepted in advance by the logistics manager at Step 6, as shown in Table 6. In Table 6, the two columns that are highlighted as blue are used to set the durations spreadsheet window in Arena at Step 5. Together with the declared time interval number, as shown in Table 7, the simulation model can be performed automatically.

Table 2: Selected Parameters

\begin{tabular}{c|l|c|c}
\hline \multicolumn{1}{c|}{ Performance } & Parameters & Unit \\
\hline \multirow{3}{*}{$\begin{array}{c}\text { Checking } \\
\text { operation }\end{array}$} & Checking for beverage products & TRIA(0.72,1.33,1.95) & Min./Pallet \\
& Checking for products with returnable or cardboard packin & TRIA $(0.51,0.60,0.73)$ & Min./Pallet \\
& Checking for small quantity orders & TRIA $(0.19,0.20,0.25)$ & Second/Piece \\
& Adding four-wheelers for beverage products & TRIA $(0.22,0.27,0.32)$ & Min./Pallet \\
\hline \multirow{5}{*}{$\begin{array}{c}\text { Prep. sorting } \\
\text { operation }\end{array}$} & Unpacking cardboard & TRIA $(0.23,0.93,1.86)$ & Min./Pallet \\
& Prep. sorting for returnable or cardboard packing & TRIA $(1.34,2.16,3.27)$ & Min./Pallet \\
& Prep. sorting for small quantity orders & TRIA $(0.07,0.1,0.12)$ & Min./Piece \\
& Return a roll-box-pallet & TRIA $(0.44,0.56,0.78)$ & Min./Pallet \\
\hline \multirow{2}{*}{ Sorting operation } & Take a four-wheeler & TRIA $(0.43,0.47,0.55)$ & Min./Pallet \\
& Load to a cart & TRIA $(0.20,0.50,1.00)$ & Min./Item \\
& Scan barcode of products & TRIA $(0.12,0.17,0.24)$ & Min./Item \\
& Sorting & TRIA $(1.39,2.76,4.1)$ & Min./Piece \\
\hline
\end{tabular}

Table 3: Product Attributes

\begin{tabular}{|c|c|c|c|c|c|c|c|}
\hline Product code & $\begin{array}{l}\text { Supplier } \\
\text { code }\end{array}$ & $\begin{array}{l}\text { Small quantity } \\
\text { orders }=1 ;\end{array}$ & $\begin{array}{l}\text { Beverage } \\
\text { products }=1 ;\end{array}$ & $\begin{array}{l}\text { Returnable packing } \\
=1 \text {; Cardboard }\end{array}$ & $\begin{array}{c}\text { Returnable } \\
\text { container type }\end{array}$ & $\begin{array}{l}\text { Maximum case } \\
\text { quantity on one four- }\end{array}$ & PCS in box \\
\hline 1721089 & 15 & 0 & 0 & 1 & 11 & 7 & 24 \\
\hline 1721133 & 15 & 0 & 1 & 1 & 4 & 10 & 20 \\
\hline 1748307 & 15 & 0 & 1 & 1 & 4 & 10 & 20 \\
\hline 1748314 & 15 & 0 & 1 & 1 & 4 & 10 & 20 \\
\hline 1748321 & 15 & 0 & 1 & 1 & 4 & 10 & 20 \\
\hline 1748352 & 15 & 0 & 1 & 1 & 4 & 10 & 12 \\
\hline 1748369 & 15 & 0 & 1 & 1 & 4 & 10 & 12 \\
\hline 1748376 & 15 & 0 & 1 & 1 & 4 & 10 & 12 \\
\hline 1930061 & 15 & 0 & 0 & 1 & 10 & 10 & 20 \\
\hline 1730067 & 12 & 0 & 0 & 0 & - & 64 & 12 \\
\hline$:$ & $:$ & $:$ & $:$ & $:$ & $:$ & $:$ & $:$ \\
\hline
\end{tabular}

Table 4: Demand Data from Stores

\begin{tabular}{|c|c|c|c|c|c|c|c|c|c|c|c|c|}
\hline Product code & Store 1 & Store 2 & Store 3 & Store 4 & Store 5 & Store 6 & Store 7 & Store 8 & Store 9 & \begin{tabular}{|l|} 
Store 10 \\
\end{tabular} & $\ldots$ & Store 236 \\
\hline 1721089 & & 4 & & & & & & & & & & 3 \\
\hline 1721133 & 6 & 5 & & 3 & 3 & & & 5 & 6 & 3 & $\ldots$ & 5 \\
\hline 1748307 & 3 & & 3 & 3 & & 4 & 3 & & 3 & & $\ldots$ & 3 \\
\hline 1748314 & & & & & & 4 & 4 & 3 & & & $\ldots$ & \\
\hline 1748321 & 3 & 3 & 3 & 5 & & & 4 & & 3 & & $\ldots$ & 3 \\
\hline 1748352 & & & & & & & & & & 3 & $\ldots$ & \\
\hline 1748369 & & & & & & & & & & & & \\
\hline 1748376 & 3 & & & & & & 4 & & 3 & & $\ldots$ & \\
\hline 1930061 & & & & & & & 10 & & & & $\ldots$ & 3 \\
\hline 1730067 & 9 & & & 3 & & & & & & 6 & $\ldots$ & 3 \\
\hline 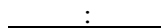 & : & : & : & : & & : & & : & : & : & : & : \\
\hline
\end{tabular}




\section{Liu and Takakuwa}

Table 5: Arrival Time of Suppliers

\begin{tabular}{c|c}
\hline Supplier code & Arrival time \\
\hline 001 & 1345 \\
002 & 1320 \\
003 & 1245 \\
004 & 1340 \\
005 & 1600 \\
$\cdot$ & $\cdot$
\end{tabular}

Table 6: Operator Schedules

\begin{tabular}{|c|c|c|c|c|c|c|}
\hline Operator No. & Operator Name & Skill-type & Beginning Time & Finishing Time & Working Quarterhours & Working Hours \\
\hline 1 & Operator 1 & 3 & 0 & 26 & 26 & 6.50 \\
\hline 2 & Operator 2 & 2 & 1 & 27 & 26 & 6.50 \\
\hline 3 & Operator_3 & 3 & 2 & 12 & 10 & 2.50 \\
\hline 4 & Operator 4 & 1 & 2 & 19 & 17 & 4.25 \\
\hline : & : & : & : & : & : & : \\
\hline 12 & Operator 12 & 2 & 2 & 19 & 17 & 4.25 \\
\hline
\end{tabular}

Table 7: Declared Time Interval Number

\begin{tabular}{c|c|c|c|c|c|c}
\hline Time & $12: 45$ & $13: 00$ & $13: 15$ & $13: 30$ & $\cdots$ & $19: 45$ \\
\hline Declared Number & 0 & 1 & 2 & 3 & $\cdots$ & 28 \\
\hline
\end{tabular}

\subsection{Performance Analysis}

By performing the simulation at Step 7, an animation along with dynamic statistics and graphs provides a general view of the system operation. The animation model used in this study was constructed with Arena 3D player, as shown in Figure 1. The animation of the material handling operation can be validated by comparing with the actual system performance.

A Gantt chart of operation status by statistics in Arena is shown in Figure 6. From the figure, the beginning and ending times for each item from each supplier can be estimated, and the operation risks can be examined, which estimates whether all the operation activities can be finished on time.

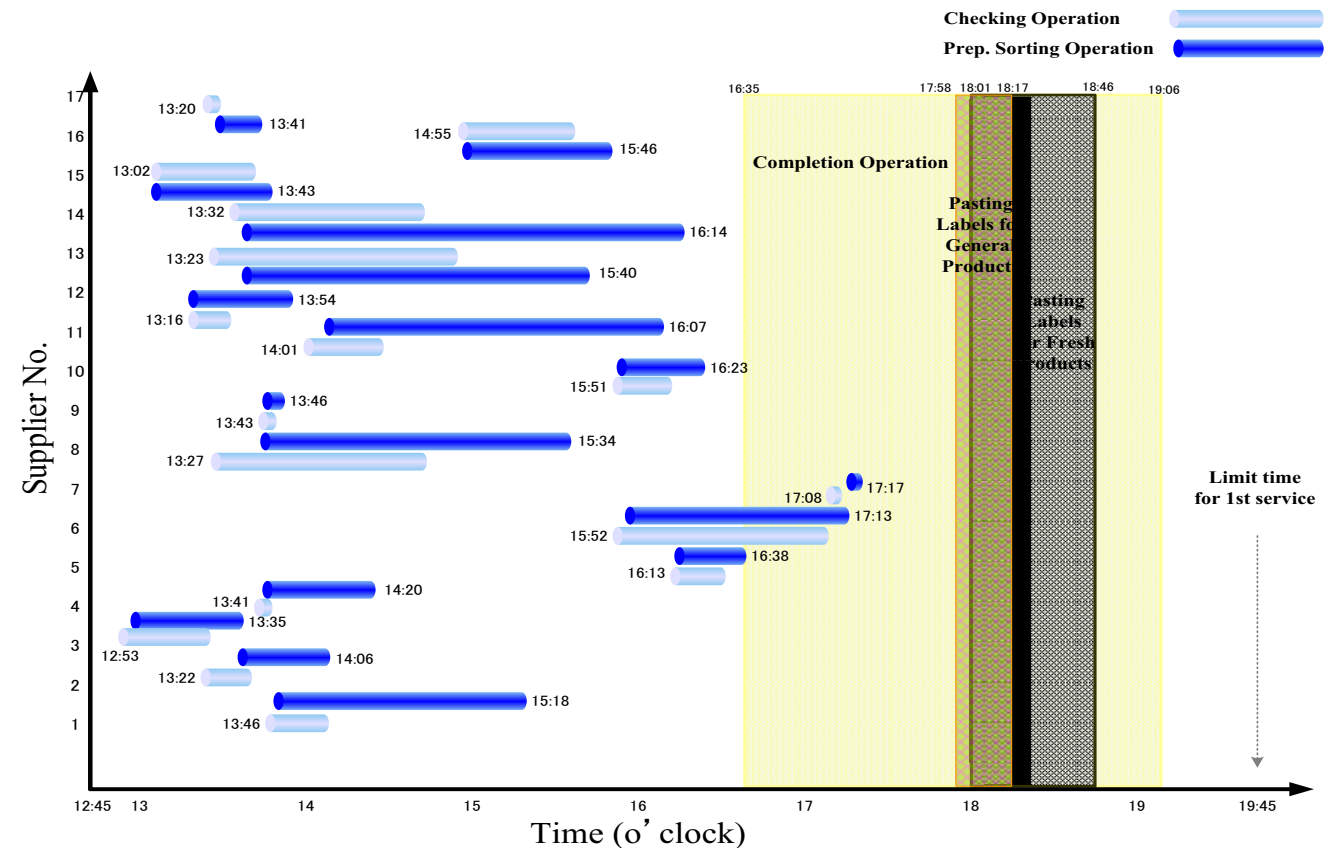

Figure 6: Operation Status (Gantt Chart) 


\section{Liu and Takakuwa}

After the simulation, the $95 \%$ confidence intervals for the average percentage of the inbound dock utilization and the scheduled utilization of the prep. sorting operators are outputted, as shown in Figures 7 and 8 , respectively. The confidence intervals provide the critical decision-making support about inbound schedules and operators shifts for the logistics managers. The man-hour requirement for each operation at each work-hour is obtained, as shown in Figure 9. According to the results, the peak time for checking operation appears during the 2nd work-hour, while the peak time for prep. sorting operation appears between the 2nd and 4th work-hour. This result can be used to examine the balance of operation loads at the cross-docking center. These results show that the simulation based approach can provide a flexible tool for logistics managers to optimize the operations of the material handling operation, especially when under dynamic and complicated circumstances.

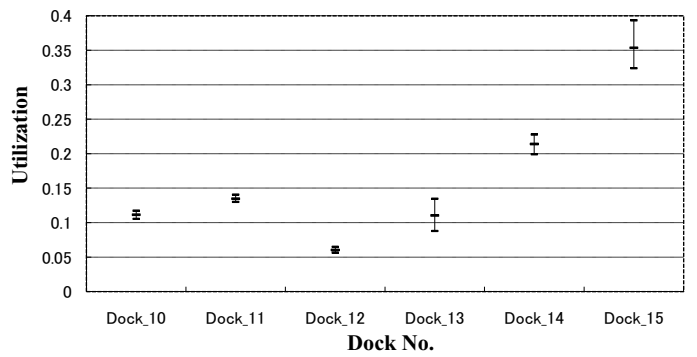

Figure 7: 95\% Confidence Interval for the Average Percentage of the Inbound Dock Utilization

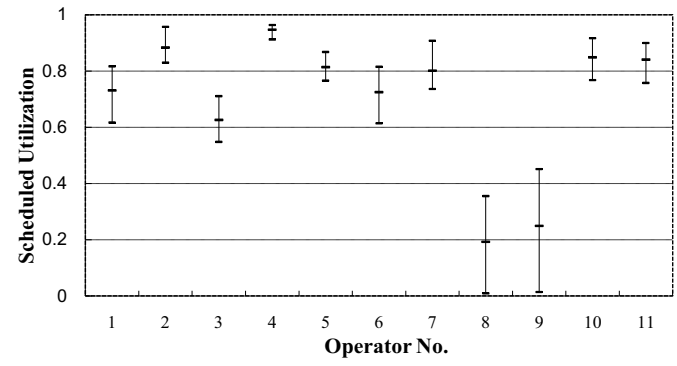

Figure 8: 95\% Confidence Interval for the Average Percentage of Operator Scheduled Utilization

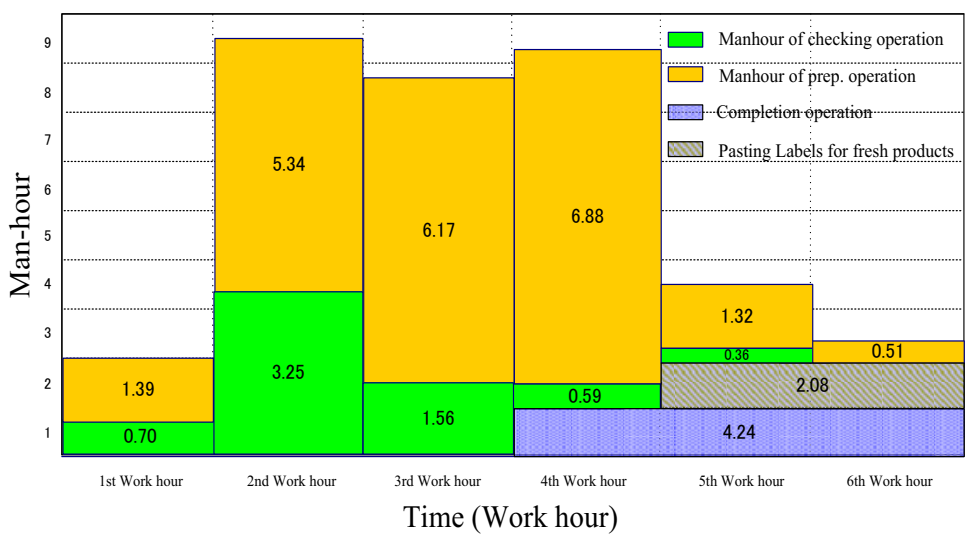

Figure 9: Man-hour Requirement for Each Operation Activity 


\section{Liu and Takakuwa}

\section{CONCLUSIONS}

A simulation model of the material handling operation was constructed and used to improve the performance and reduce loads of operations for a typical non-automated cross-docking center within a retail environment.

A systematic and flexible procedure for the consecutive operations of material handling was described as a decision-support tool that provides critical support for logistics managers. The procedure considers the dynamic logistics operation information.

The proposed procedure was applied to an actual cross-docking center. Material handling was modelled by a simulation to analyze the performance of operations. The results showed that the proposed procedure is both practical and powerful in assisting logistics managers with their continuous and efficient decision-making efforts.

In future research, other indicators will be analyzed as a performance measure to improve congestion of both merchandise and operators within the cross-docking center.

\section{ACKNOWLEDGMENTS}

The authors wish to express sincere gratitude to FamilyMart Company, Ltd. and HAMAKYOREX Company, Ltd. for their cooperation in completing this research. Special thanks should be expressed to Mr. Ueda, Mr. Takahashi, and Mr. Fujita of FamilyMart Corporation, and Mr. Takasugi and Mr. Masuta of HAMAKYOREX Corporation in supporting this research effort. This research was supported by Grantin-Aid for Asian CORE Program of Japan Society for the Promotion of Science (JSPS).

\section{REFERENCES}

Amato, F., F. Basile, C. Carbone, and P. Chiacchio. 2005. An approach to control automated warehouse systems. Control Engineering Practice 13, 1223-1241.

Burnett, D., and T. LeBaron. 2001. Efficiently modeling warehouse systems. In Proceedings of the 2001 Winter Simulation Conference, ed. B. A. Peters, J. S. Smith, D. J. Medeiros, and M. W. Rohrer, 1001-1006. Piscataway, New Jersey: Institute of Electrical and Electronics Engineers, Inc.

Cooper, J. 1994. Logistics distribution planning. 2nd ed. London: Kogan Page.

Gebennini, E., S. Dallari, A. Grassi, G. Perrica, C. Fantuzzi, and R. Gamberini. 2008. A simulation based approach for supporting automated guided vehicles (AGVs) systems design. In Proceedings of the 2008 Winter Simulation Conference, ed. S. J. Mason, R. R. Hill, L. Monch, O. Rose, T. Jefferson, and J. W. Fowler, 2156-2163. Piscataway, New Jersey: Institute of Electrical and Electronics Engineers, Inc.

Harmonosky, C.M., and R. P. Sadowski. 1984. A simulation model and analysis: integrating AGVs with non-automated material handling. In Proceedings of the 1984 Winter Simulation Conference, ed. S. Sheppard, U. W. Pooch, and C. D. Pegden, 178-183. Piscataway, New Jersey: Institute of Electrical and Electronics Engineers, Inc.

Johnson, A., H. J. Carlo, J. A. Jimenez, D. Nazzal, and V. Lasrado. 2009. A greedy heuristic for location crossovers in conveyor-based AMHS in wafer fabs. In Proceedings of the 2009 Winter Simulation Conference, ed. M. D. Rossetti, R. R. Hill, B. Johansson, A. Dunkin, and R. G. Ingalls, 1667-1676. Piscataway, New Jersey: Institute of Electrical and Electronics Engineers, Inc.

Kelton, W. D., R. P. Sadowski, and D. T. Sturrock. 2007. Simulation with ARENA. 4th ed. New York, NY: McGraw-Hill Co., Inc.

Kulwiec, R. A., ed. 1994. Retail distribution: custom handling that goes with the flow. Modern Materials Handling 49(6): 30-33.

Liu, Y., and S. Takakuwa. 2009. Simulation-based personnel planning for materials handling at a crossdocking center under retail distribution environment. In Proceedings of the 2009 Winter Simulation 


\section{Liu and Takakuwa}

Conference, ed. M. D. Rossetti, R. R. Hill, B. Johansson, A. Dunkin, and R. G. Ingalls, 2414-2425. Piscataway, New Jersey: Institute of Electrical and Electronics Engineers, Inc.

Macro, J. G., and R. E. Salmi. 2002. A simulation tool to determine warehouse efficiencies and storage allocations. In Proceedings of the 2002 Winter Simulation Conference, ed. E. Yucesan, C. H. Chen, J. L. Snowdon, and J. M. Charnes, 1001-1006. Piscataway, New Jersey: Institute of Electrical and Electronics Engineers, Inc.

Magableh, G. M., and M. Rossetti. 2005. Modeling and analysis of a general cross-docking facility. In Proceedings of the 2005 Winter Simulation Conference, ed. M. E. Kuhl, N. M. Steiger, F. B. Armstrong, and J. A. Joines, 1613-1620. Piscataway, New Jersey: Institute of Electrical and Electronics Engineers, Inc.

Medeiros, D. J., E. E. Enscore, and A. Smith. 1986. Performance analysis of miniload systems. In Proceedings of the 1986 Winter Simulation Conference, ed. J. R. Wilson, J. O. Henriksen, and S. D. Roberts, 606-612. Piscataway, New Jersey: Institute of Electrical and Electronics Engineers, Inc.

Medina, L. A., R. U. Bilsel, R. A. Wysk, W. Prabhu, and A. R. Ravindran. 2009. Simulation for predictive control of a distribution center. In Proceedings of the 2009 Winter Simulation Conference, ed. M. D. Rossetti, R. R. Hill, B. Johansson, A. Dunkin, and R. G. Ingalls, 2426-2435. Piscataway, New Jersey: Institute of Electrical and Electronics Engineers, Inc.

Muller, D. 1989. AS/RS and warehouse modeling. In Proceedings of the 1989 Winter Simulation Conference, ed. E. A. MacNair, K. J. Musselman, and P. Heidelberger, 802-810. Piscataway, New Jersey: Institute of Electrical and Electronics Engineers, Inc.

Rohrer, M. 1995. Simulation and cross docking. In Proceedings of the 1995 Winter Simulation Conference, ed. C. Alexopoulos, K. Kang, W. R. Lilegdon, and D. Goldsman, 846-849. Piscataway, New Jersey: Institute of Electrical and Electronics Engineers, Inc.

Takakuwa, S. 1994. Precise modeling and analysis of large-scale AS/RS. In Proceedings of the 1994 Winter Simulation Conference, ed. M. D. Rossetti, R. R. Hill, B. Johansson, A. Dunkin, and R. G. Ingalls, 1001-1007. Piscataway, New Jersey: Institute of Electrical and Electronics Engineers, Inc.

Takakuwa, S. 1995. Flexible modeling and analysis of large-scale AS/RS-AGV systems. In Proceedings of the 1995 Winter Simulation Conference, ed. C. Alexopoulos, K. Kang, W. R. Lilegdon, and D. Goldsman, 873-880. Piscataway, New Jersey: Institute of Electrical and Electronics Engineers, Inc.

Takakuwa, S. 1996. Efficient module-based modeling for a large-scale AS/RS-AGV system. In Proceedings of the 1996 Winter Simulation Conference, ed. J. M. Charnes, D. J. Morrice, D. T. Brunner, and J. J. Swain, 1141-1148. Piscataway, New Jersey: Institute of Electrical and Electronics Engineers, Inc.

Takakuwa, S., H. Takizawa, K. Ito, and S. Hiraoka. 2000. Simulation and analysis of non-automated distribution warehouse. In Proceedings of the 2000 Winter Simulation Conference, ed. J. A. Joines, R. R. Barton, K. Kang, and P. A. Fishwick, 1177-1184. Piscataway, New Jersey: Institute of Electrical and Electronics Engineers, Inc.

Zhou, M., K. Setavoraphan, and Z. Chen. 2005. Conceptual simulation modeling of warehousing operation. In Proceedings of the 2005 Winter Simulation Conference, ed. M. E. Kuhl, N. M. Steiger, F. B. Armstrong, and J. A. Joines, 1621-1626. Piscataway, New Jersey: Institute of Electrical and Electronics Engineers, Inc.

\section{AUTHOR BIOGRAPHIES}

YAN LIU is an Assistant Professor at Graduate School of Economics and Business Administration at Nagoya University in Japan. She received her B.Sc. and M. Sc. Degrees in Economics from the HLJ Agriculture University of China in 2001 and from Nagoya university of Japan in 2006. She received her Ph.D. from the Graduate School of Economics and Business Administration at Nagoya University of Japan in 2010. Her research interests include demand forecast using data mining technology and simulation analysis of manufacturing and logistics systems. Her current research focuses on the optimization of lo- 


\section{Liu and Takakuwa}

gistics systems. Her email is $<1$ iu-yane soec nagoya-u.ac.jp>.

SOEMON TAKAKUWA is a Professor in the Graduate School of Economics and Business Administration at Nagoya University in Japan. He received his B. Sc. and M. Sc. degrees in industrial engineering from Nagoya Institute of Technology in 1975 and Tokyo Institute of Technology in 1977 respectively. His Ph.D. is in industrial engineering from The Pennsylvania State University. He holds a Doctorate of Economics from Nagoya University. He holds a P.E. in Industrial Engineering. His research interests include the optimization of manufacturing and logistics systems, management information systems and simulation analysis on these systems in the context of hospitals. He prepared the Japanese editions of both Introduction to simulation using SIMAN and Simulation with ARENA. He serves concurrently as the senior staff of Department of Hospital Management Strategy and Planning at Nagoya University Hospital, too. His email is <takakuwa@soec.nagoya-u.ac.jp>. 